\title{
Charting and Documenting Spiritual Care in Health Services: Victoria, Australia
}

\author{
Christine Hennequin
}

Diverse models of chaplaincy and spiritual care have existed in health services in Australia for decades. This overview of charting will address the development in the state of Victoria from the perspective of Spiritual Health Association as a peak body for spiritual care in health services (Spiritual Health Association 2020). Some of these developments have been driven by national standards in charting and data collection and consequently have had some impact in the spiritual care sector nationally. Funding sources and the models of delivery have evolved and changed quite significantly since the 1950 s to a more professional model, and this evolution has necessitated changes in accountability, including charting and documentation.

\section{Background/Rationale}

In Victoria, a state in south-eastern Australia, chaplaincy has moved from mainly following a Christian-delivered model established by churches in the 1950s and 1960s to current models of spiritual care responding to all faiths and beliefs. In the 1950s the Anglican Church employed its first Chaplain at the Royal Melbourne Hospital in Melbourne (Kenny 2003). John Moroney established professional procedures in his role. Catholic Chaplaincy was well established by the 1960 s with a part-time Catholic Chaplain employed at the Royal Women's Hospital in 1961 for sacramental ministry and education and gatherings of mental health and hospital chaplains from several denominations occurred in the 1950s and 1960s (Kenny 2003).

Today, most major metropolitan public hospitals in Melbourne and some regional hospitals in Victoria employ a Spiritual Care Manager, Director or Coordinator with varying numbers of professional staff employed by the health service or by a faith

\footnotetext{
C. Hennequin ( $\triangle)$

Spiritual Health Association, Collingwood, VIC, USA

e-mail: development@spiritualhealth.org.au
} 
community. Some private hospitals, especially denominational hospitals, employ spiritual care staff. Some health services conduct a Clinical Education programme concurrently and use trained and supervised Clinical Pastoral Education students as part of their resources. A few metropolitan and many regional health services use volunteers with a limited scope of practice as part of the model of providing spiritual care.

\section{The 1990s: Developing Pastoral Diagnoses}

The Austin Hospital joined other Allied Health departments in 1992 to develop codes to document their work. Graeme D. Gibbons, together with pastoral care supervisors and colleagues at the Austin Repatriation Hospital, developed diagnoses and interventions which were used to document pastoral care provision in an Allied Health statistical package (Gibbons 1998). As a Clinical Pastoral Education student doing my first unit at the Austin in 1993, I used these codes and participated in education regarding the diagnoses and interventions, their descriptions and interpretation as we reflected on our work on the wards. The Pastoral Care Casemix Project initiated by Gibbons and other medical centre chaplains was influenced significantly by Clinical Pastoral Education (Gibbons 1998) and was important in establishing pastoral care codes which "Integrated information technology with a foundational theological perspective and the traditions associated with CPE and hospital ministry" (Kenny 2003).

Incorporating these diagnoses alongside other allied health disciplines in the health services' database was an important step in demonstrating the contribution and value of pastoral care within the broader healthcare context. Research and analysis of the data from January 1993 to May 1998 provided information about the chaplains' core activities which included "promoting spiritual transcending" (57\% of all entries), "promoting spiritual intactness" (36.1\%) and "enacting ministry (6.2\%)" (Kenny 2003).

Skills and interest in charting have varied and have relied for a long time on the personal interest or skill of spiritual care managers. In his thesis on chaplains in South Australia, C.C. Aiken found that some paid close attention to this aspect of their role, while others saw administration, including collecting statistics, as a frustrating aspect of their role as hospital chaplains (Aiken 2010). Yet both the relational and administrative aspects of the role are important.

\section{Guidelines for Pastoral Care in Australia}

In the early 2000s, health services in Victoria still had diverse and individual ways of documenting spiritual care. Work was being done on several fronts to set standards for assessing and recording pastoral interventions. In 2002, the Australian 
College of Chaplains requested the inclusion of pastoral care intervention codes for the Third Edition of ICD10-AM (National Centre for Classification in Health 2002). ${ }^{1}$ The pastoral codes were disseminated and enthusiastically received by members at the Australian Health and Welfare Chaplains Association's (AHWCA) ${ }^{2}$ national conference that year. The AHWCA published the Health Care Chaplaincy Guidelines in 2004 after extensive consultation, review and evaluation of a draft document in 2002. These guidelines were based on "the UK 'Health Care Chaplaincy Standards' as a national response to formulating a systematic approach for pastoral care and chaplaincy services across Australia" (Australian Health and Welfare Chaplains Association Inc. 2004).

The Guidelines Map clearly states the importance of charting and accurate documentation of pastoral care services as one of the competencies necessary in a systematic approach to providing services:

- D2 Provide and record pastoral care services

- D2.3 Assess patient's pastoral diagnoses

- D2.4 Assess individual spirituality and strength

- D2.5 Chart pastoral interventions into patient records (where permitted)

- D2.6 Codify and enter details into pastoral care database

- D2.7 Retrieve data from database

(Australian Health and Welfare Chaplains Association Inc. 2004)

The Healthcare Chaplaincy Council ${ }^{3}$ of Victoria commissioned further work to produce standards and a minimum dataset for reporting pastoral care in a consistent and accountable manner in public and private hospitals over the next decade (Healthcare Chaplaincy Council of Victoria Inc. 2012). Standards were also developed for the mental health and aged care sectors. Standardisation was required to encourage practitioners to describe and collect information using consistent language and categories and to improve data collection within their health services so that pastoral care interventions would be visible and reported to management.

\footnotetext{
${ }^{1}$ ICD-10-AM is the International Statistical Classification of Diseases and Related Health Problems, Tenth Revision, Australian Modification. It consists of a tabular list of diseases and accompanying index.

${ }^{2}$ AHWCA, the Australian Health and Welfare Chaplains Association, was the association representing chaplains until 2010. It was replaced by the new national association Spiritual Care Australia in February 2010.

${ }^{3}$ The Healthcare Chaplaincy Council of Victoria and Spiritual Health Victoria are the precursors to Spiritual Health Association, the peak body for spiritual care in health services. The name changes occurred in June 2014 and July 2019, respectively.
} 


\section{A New Minimum Dataset}

In 2013-2014 the Department of Health and Human Services requested that Spiritual Health Association report on spiritual care activity from public hospitals as part of its funding requirement. The department was particularly interested in information about spiritual care interventions by clergy and faith representatives as well as faith-based volunteers. Part of Spiritual Health Association's funding from the department is disbursed to faith groups, and increased accountability was required of them. Spiritual Health Association kept abreast of international developments in the area of documentation and reporting and followed with interest the work that was being done by Dean V. Marek in Milwaukee regarding identifying the cost of chaplaincy interventions (Marek 2005) and of Massey et al. regarding a taxonomy of terms for spiritual care (Massey 2015). The requirement for effective documentation and clear accountability and the focus on quality and safety remains following the recommendations of Targeting Zero: the review of safety and quality assurance in Victoria (Safer Care Victoria 2018; Spiritual Care Australia 2018).

The pilot project engaged spiritual care managers from 23 health services who collaborated with Spiritual Health Association to provide the data for spiritual care activity. During the process of data collection, it became clear that they were not collecting data in a consistent manner. There were no specific guidelines for the sector, and some practitioners were unaware of existing national standards or did not know how they were to be applied in data collection. A Working Group consisting of nine spiritual care managers from metropolitan hospitals met with Spiritual Health Association staff over eighteen months to develop a new Spiritual Care Minimum Dataset Framework based on current health data standards and definitions (Spiritual Health Victoria 2015). Once completed, the framework was circulated to Chief Executive Officers of health services with a spiritual care department and to spiritual care management at those sites. Education sessions were held by Spiritual Health Association for managers and senior practitioners, and a workshop was presented at the national Spiritual Care Conference in Sydney in 2016 with an additional framework: Spiritual Care in Victorian Health Services: Towards Best Practice Framework. This framework helped to improve the quality and consistency of data collection as part of best practice. There has been national interest in the framework as it provided guidance in the use of the ICD-10-AM/ACHI/ $\mathrm{ACS}^{4}$ codes

\footnotetext{
${ }^{4} \mathrm{ACHI}$, the Australian Classification of Health Interventions, has also been in use since 1998. ACHI was based on the Medicare Benefits Schedule (MBS) and was previously known as the Medicare Benefits Schedule-Extended (MBS-E). The National Centre for Classification in Health developed it with assistance from specialist clinicians and clinical coders. ACHI codes have seven digits. The first five digits are the Medicare Benefit Schedule (MBS) item number where one exists. The two-digit extension represents specific interventions included in that item. The classification is structured by body system, site and intervention type. Interventions not currently listed in MBS have also been included (e.g. dental, allied health interventions, cosmetic surgery). ACHI consists of a tabular list of interventions and accompanying alphabetic index. ACS, the Australian Coding Standards, have been developed with the objective of satisfying sound coding conventions
} 
which are used nationally (Independent Hospital Pricing Authority 2018) to report on activity-based funding. The framework has also been used to establish a minimum dataset for a new spiritual care service at the Central Adelaide Local Health Network in South Australia (Bossie 2018).

\section{Towards a Best-Practice Approach}

The focus on documentation and data collection and the significant work undertaken by the Healthcare Chaplaincy Council of Victoria and subsequently by Spiritual Health Association over the last two decades has assisted our sector in Victoria to become more competent in this area. Preliminary data from a recent state-wide survey conducted by Spiritual Health Association in 2019 suggests that there has been an increase in the number of spiritual care departments using the ICD-10-AM/ ACHI/ACS intervention codes (Spiritual Health Association 2019b). Documenting in medical records is an essential requirement in a complex health service environment. Spiritual Care departments have worked to improve this aspect of reporting in Victoria. While the skills of practitioners vary, there are some managers who are very interested in and engaged with data collection and charting. Ongoing consultation with spiritual care managers and practitioners through regular updates, workshops and Spiritual Care Management Network meetings keeps data collection and charting on the agenda (Spiritual Health Victoria 2018; Spiritual Care Australia 2018).

As part of its goal and mission, ${ }^{5}$ Spiritual Health Association has identified and responded to the strategic issues for spiritual care within healthcare and encouraged the sector in Victoria to support and collaborate with it. Spiritual Health Association's Capability Framework 2016 (Spiritual Health Victoria 2016) and the Spiritual Care Australia Standards of Practice (Spiritual Care Australia 2014) recognise documentation as an essential skill for practitioners and for volunteers. Developing this as a foundational skill when delivering Clinical Pastoral Education and when training new practitioners is paramount for the future.

The Spiritual Care Minimum Data Set Framework was evaluated in late 2016 by surveying spiritual care management and was reviewed in 2018. Evaluation results were positive and demonstrated that this significant work has assisted our sector in Victoria to become more engaged with data collection and to recognise its importance in the provision of healthcare. Ongoing consultation with managers, and practitioners, health service executives and health information administrators during the revision has ensured that the new guidelines reflect current practice, standards and language.

for use with ICD-10-AM and ACHI. They apply to all public and private hospitals in Australia. The ongoing revision of the Australian Coding Standards ensures that they reflect changes in clinical practice, clinical classification amendments and various user requirements of inpatient data collections.

${ }^{5}$ Spiritual Health Association's mission is to enable the provision of quality spiritual care as an integral part of all health services in Australia. 
The new guideline "Spiritual Care in Medical Records: A Guide to Reporting and Documenting Spiritual Care in Health Services" (Spiritual Health Association 2019a) aligns with current practice in health services and the current National Safety and Quality Health Service Standards (Australian Commission on Safety and Quality in Health Care 2017) as well as the updated Spiritual Intervention Codes from the Australian Consortium for Classification Development (Independent Pricking Authority 2018). The guideline was circulated to Victorian health services and spiritual care managers and to other key stakeholders in February 2019. It is available on the Spiritual Health Association website (Spiritual Health Association 2019).

Spiritual care departments that are well integrated adhere to their health service's policy and to the current guidelines on documenting in medical records. As a result, communication within the multidisciplinary team is enabled and standards are met. In addition, the guidelines assist in educating spiritual care staff and students about documentation and charting. Staff can develop their capability in that area and meet the requirements of their role.

The following are case studies of documentation in three health services in Victoria, Australia. Data collected electronically and in paper-based form by the health service is used in different ways for reporting at different levels of the health system:

- By the spiritual care department to collect a detailed account of spiritual care provision by identifying patients' needs, spiritual care interventions and outcomes

- By the spiritual care department to report to management for internal reporting of the number of episodes of patient care including direct patient contact and indirect contacts such as administration and travel

- By the health service to report to the Department of Health and Human Services in Victoria by mapping and transmitting aggregate data according to the reporting requirements and business rules each financial year ${ }^{6}$

\section{Case Studies}

\subsection{The Royal Melbourne Hospital: Parkville, Victoria, Australia}

The Royal Melbourne Hospital is a large metropolitan hospital in inner Melbourne and is part of Melbourne Health. The hospital still uses paper files in conjunction with an electronic system, Patient Flow Manager, which manages the patient jour-

\footnotetext{
${ }^{6}$ While spiritual care is not costed as part of Casemix funding in Victoria (Victoria State Government 2018a, b, c), it is included with other Allied Health interventions as part of the Not Automatically Qualified for Admission List (NAQAL) in the Victorian Admitted Episodes of Care Dataset procedure code list 2017-2018 (Victorian state Government 2018).
} 
ney from admission to discharge. It includes a referral system where Allied Health referrals, including spiritual care, can be made. Currently, some medical records are still paper-based.

Multidisciplinary colleagues communicate in the Patient Flow Manager to request a referral from another discipline. Spiritual Care will accept the referral and provide an update to the referring colleague by providing information about the spiritual care interventions and time frames in which follow-up will occur.

Figure 1 is an image of the Patient Flow Manager system.

In addition, spiritual care practitioners use free text when writing Clinical Progress Notes (Fig. 2) by hand in medical records. The hospital will eventually have all existing records digitalised as part of the electronic medical record system. Practitioners are urged to document significant information in the patient's Clinical Progress Notes.

Verbal communication is encouraged, especially for significant care issues (i.e. organ transplant, family meetings) and at times for debriefing between colleagues. Melbourne Health's MH05 Documentation and Records Management Policy states this clearly under Procedure 5.4b.

Documentation at the Royal Melbourne Hospital meets the recommendations of Spiritual Health Association's guidelines for documentation (Spiritual Health Victoria 2019).

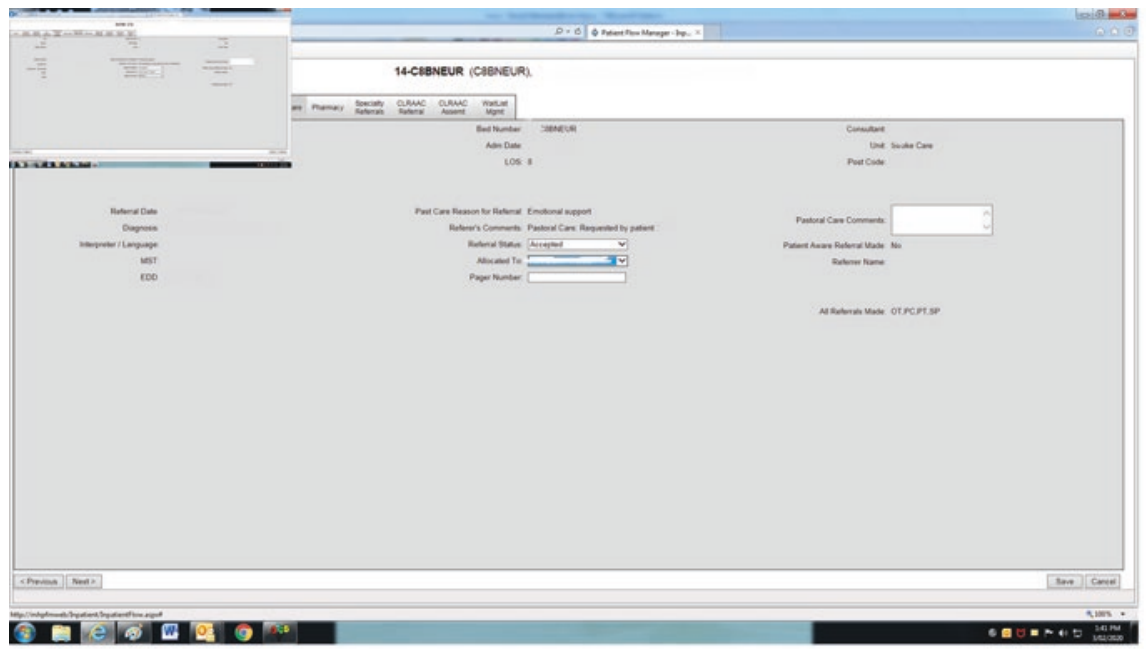

Fig. 1 Patient Flow Manager, Royal Melbourne Hospital. (Reproduced with permission from Melbourne Health. Copyright (C 2020 Melbourne Health. All rights reserved) 


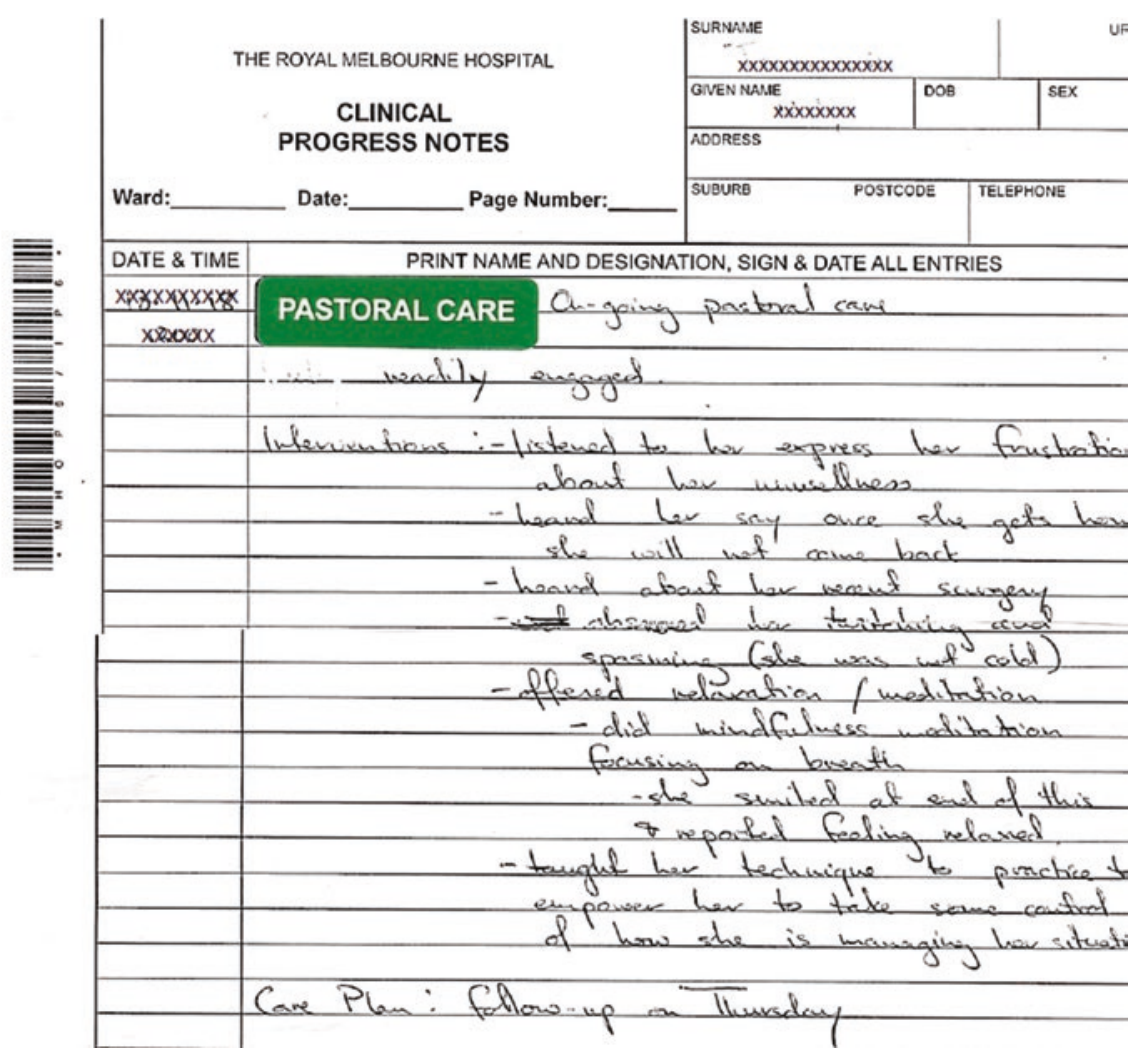

Fig. 2 Example of documentation, Royal Melbourne Hospital. (Reproduced with permission from Melbourne Health. Copyright $\odot 2020$ Melbourne Health. All rights reserved)

\subsection{Bendigo Health}

Bendigo Health is a regional health service in the state of Victoria. Bendigo Health employs a Manager of Pastoral Care and a Chaplain, both part-time. In addition, the Pastoral Care Department relies on a number of faith community representatives and volunteers to provide spiritual care within a specified scope of practice (Spiritual Health Victoria 2016). Documentation takes several forms: electronic and paper-based. Volunteers do not have access to the medical records, in accordance with health service policy.

To enable chaplains and religious visitors to document their visits, the Manager of Pastoral Care requested the development of form MR94H "Pastoral Care Intervention" (Fig. 3) to facilitate the documentation of four ICD-10-AM spiritual care interventions. The form could then be inserted in the medical record by Bendigo Health staff and later scanned to form part of the Digital Medical Record.

Those identified as volunteers can "tick the box" to indicate which intervention they have provided without having access to the Digital Medical Record, which is 


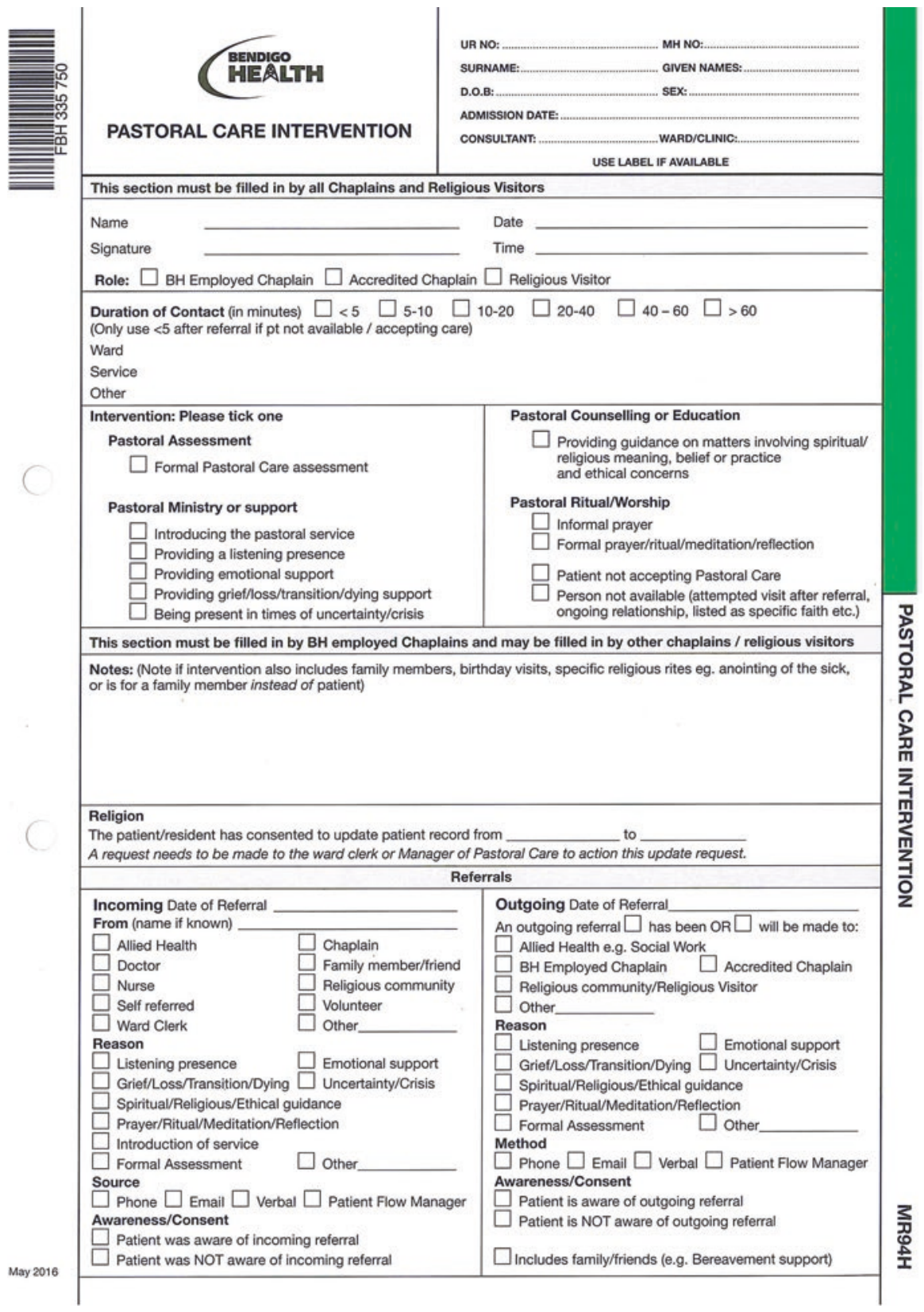

Fig. 3 Example of documentation, Bendigo Health. (Reproduced with permission from Bendigo Health. Copyright $\odot 2020$ Bendigo Health. All rights reserved) 


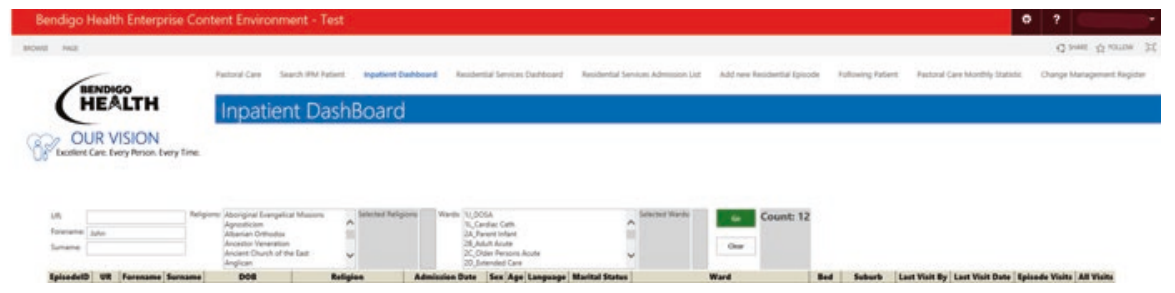

Fig. 4 Bendigo Health example. (Reproduced with permission from Bendigo Health. Copyright (C) 2020 Bendigo Health. All rights reserved)

outside of their scope. Volunteers can provide further notes about the visit and details regarding referrals as appropriate. The form avoids the duplication of requests for spiritual care and enables effective communication with the rest of the caring team.

Spiritual care practitioners and chaplains employed by their faith communities also use the MR94H form and have full access to the Digital Medical Record. Their notes would usually be more extensive to describe the spiritual care intervention provided.

The use of a digital referral flow chart has improved the efficiency of referrals. A SharePoint site is currently being developed for the Pastoral Care Department (Fig. 4). It will provide a record of completed Clinical Progress Notes MH94H forms, and chaplains will be able to access a history of spiritual care interventions for individual patients.

The Pastoral Care Department at Bendigo Health has devised a clever way to document spiritual care interventions in their medical records, while aligning itself with the health service's policy regarding who is authorised to access them. The department meets Spiritual Health Association's minimum dataset requirements. Its use of the four spiritual care interventions and descriptions of the pastoral encounter provide a common language for chaplains and volunteers to describe the spiritual care provided.

\subsection{St. Vincent's Public Hospital: Fitzroy, Victoria, Australia}

St. Vincent's Hospital is a large public hospital in inner Melbourne. Currently, St. Vincent's Hospital uses a combination of handwritten Clinical Progress Notes in paper-based medical records and electronic medical records systems for documentation. The Clinical Progress Notes are used to document the spiritual care intervention and to record the relevant themes which have emerged as part of the spiritual care encounter with the patient. The Clinical Progress Notes help to communicate with the multidisciplinary staff and provide an opportunity to educate staff about the contribution of spiritual care to patient care. A typical clinical note recording a Pastoral Encounter would read as follows: 
PASTORAL CARE: 29/11/18 10.00am. Referral received with thanks to provide pastoral care for <insert first name $>$ given teary on admission. Initial visit with <insert first name> to introduce pastoral care. Compassionate presence and active listening provided, enabling $<$ insert first name $>$ to share some life stories and reflections with themes of grief and loss. Pastoral support provided. <insert first name> expressed appreciation for the visit and requested a follow up visit which I will provide.

In one ward, clinical notes are recorded in InfoMedix - an electronic medical records system which allows for free text (Fig. 5).

In addition, spiritual care practitioners use the Patient Administration System (PAS) to record daily statistics of patient encounters. Practitioners record whether the encounter was as a result of a referral or self-referral (Comment 1 in Fig. 6) and the time taken. Comment 2 records the outcome of the encounter with an agreed descriptor as per the "Outcome Code" list. This provides common descriptors and consistent language for the practitioners to record their visits.

Descriptions of the four ICD-10-AM/ACHI/ACS spiritual care interventions are included in the drop-down boxes for "Service Type". Rituals such as "anointing" or "communion" are identified specifically as these are an important part of service provision in a Catholic public hospital.

Multidisciplinary feedback is positive regarding the contribution of spiritual care to patient care. The Pastoral Services Department are currently developing internal guidelines for patient documentation. St. Vincent's Hospital Melbourne meets Spiritual Health Association's guidelines for patient documentation (Spiritual Health Victoria 2019).

\section{Conclusion}

Advocacy for the ongoing integration of spiritual care within the health service is a priority for Spiritual Health Association. Outcomes of integration enable continuous quality improvement and meet healthcare standards as well as standards from Spiritual Care Australia. Spiritual care practitioners documenting in medical records contribute to this integration and to accountability.

Current research in Australia will add to the development of evidence-based outcome measures for spiritual care. Spiritual Health Association is collaborating with La Trobe University, Melbourne, and five health services to investigate the expectations for and the benefits from spiritual care provision. Further work on phase two and three will be undertaken this year (Spiritual Health Association 2019).

As a peak body, Spiritual Health Association needs to demonstrate that funding provided by the state government improves the quality of spiritual care in health services by ensuring evidence-based best-practice spiritual care.

The Victorian Department of Health and Human Services in 2016 has included spiritual care as an Allied Health profession in Victoria (Spiritual Health Victoria 2016). Spiritual Health Association and its representatives are invited regularly to represent the spiritual care sector on various Allied Health committees and forums 


\section{Adding an eform}
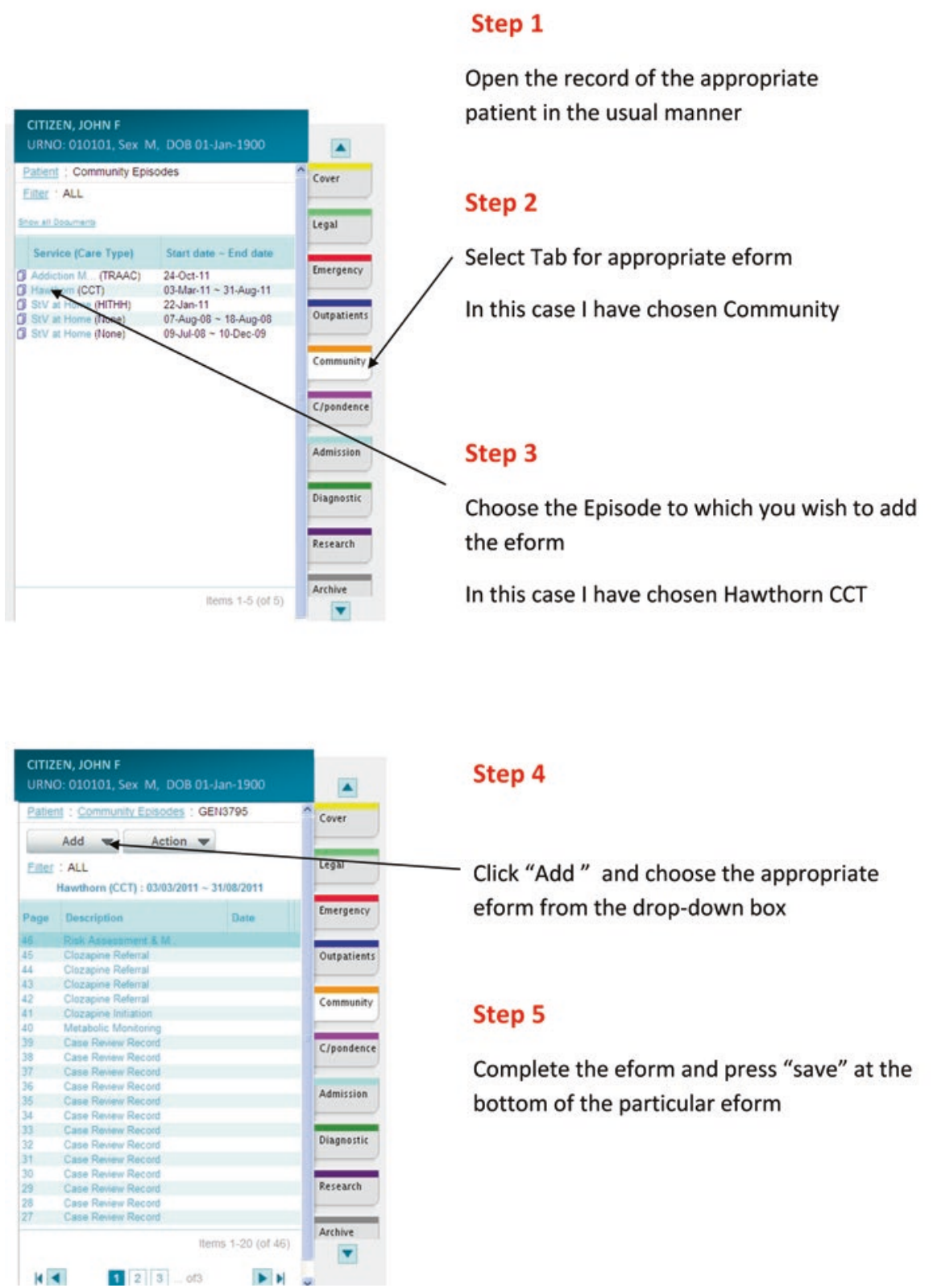

Step 4

Click "Add" and choose the appropriate eform from the drop-down box

Step 5

Complete the eform and press "save" at the bottom of the particular eform

Fig. 5 InfoMedix, St. Vincent's Public Hospital. (Reproduced with permission from St. Vincent's Hospital Melbourne Limited. Copyright () 2020 St. Vincent's Hospital Melbourne Limited. All rights reserved) 


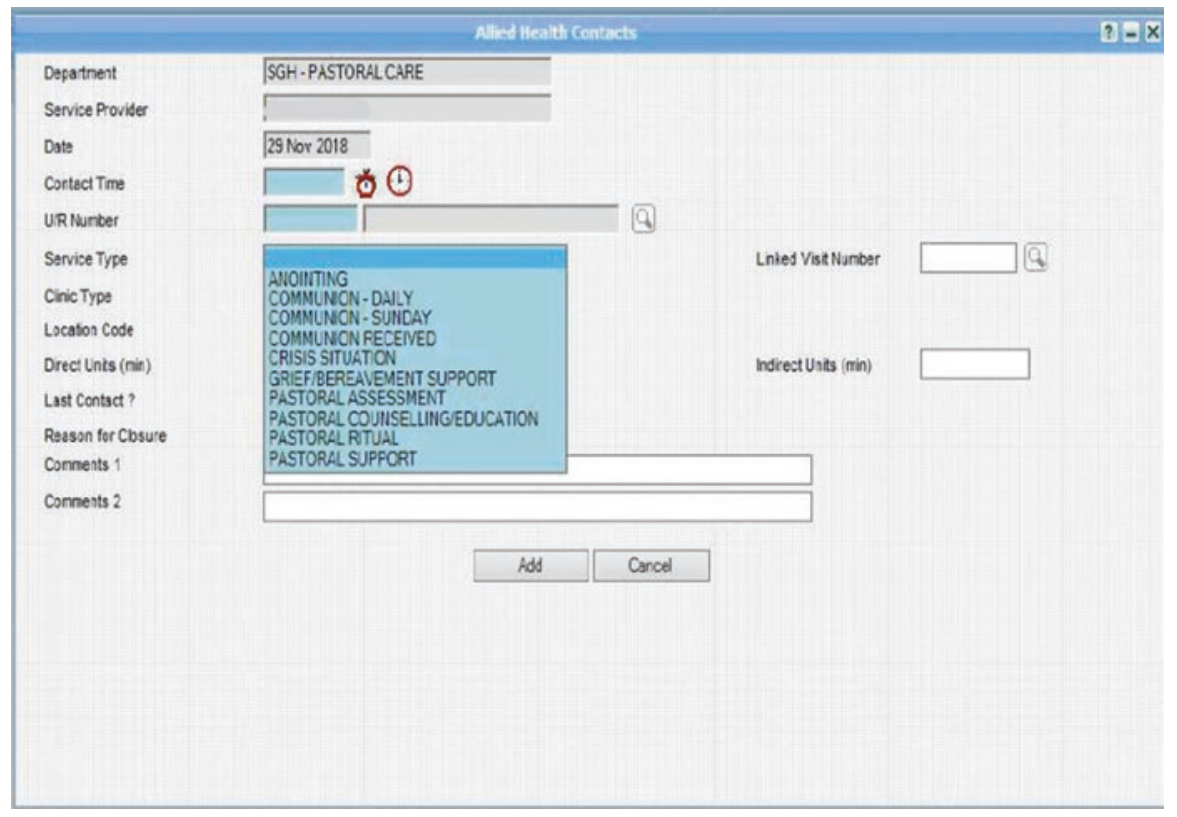

Fig. 6 PAS, St. Vincent's Public Hospital. (Reproduced with permission from St. Vincent's Hospital Melbourne Limited. Copyright @ 2020 St. Vincent's Hospital Melbourne Limited. All rights reserved)

in the Department of Health and Human Services. The full integration of spiritual care into the health system is yet to be achieved, and there are still no mandatory standards for documentation (Holmes 2018). However, having spiritual care represented at state Allied Health forums ensures that we contribute to Allied Health National Best Practice Data Sets (Victoria State Government Health and Human Services 2017) and continue to improve the quality of data that we, as a sector, provide within the health system. 


\title{
Commentary
}

\author{
Livia Wey-Meier ( $₫)$ \\ Theological Faculty of Chur, Chur, Switzerland \\ e-mail: livia.wey@mei-wey.ch
}

\begin{abstract}
Christine Hennequin's contribution speaks a different language than the previous contributions. The question of documentation is not approached here as a further reflection on the conversation had in the hospital room and on its confidentiality, nor is the internal struggle for standardisation in recording pastoral encounters put in the foreground. The article unfolds rather from the perspective of a health-political administrative office - Spiritual Health Association (SHA) is the umbrella organisation for Spiritual Care in health services in Victoria - the complete history of pastoral and spiritual services in this region. ${ }^{7}$ Three examples of a given minimum dataset to report on pastoral and spiritual services are provided.
\end{abstract}

\section{From Pastoral to Spiritual Intervention Codes}

The fact that this minimum dataset uses an official, globally accessible coding system that is almost 20 years old to record pastoral interventions may surprise some readers. In July 2002, four major "pastoral intervention" codings ("WHO-PICs") were incorporated and made available as part of the ICD-10-AM, which can be used by chaplains (or other pastoral and spiritual care workers) to record their interventions with patients and other clients (e.g. family and staff). These four major interventions are called (1) pastoral assessment, (2) pastoral ritual and worship, (3) pastoral ministry, and (4) pastoral counselling or education. Originally developed in Australia, these codes have hardly gained importance outside of Australia and have aroused little interest. Accordingly, they have rarely been evaluated in research or practice. One name from the Australian university research community that must be mentioned in this context is Lindsay B. Carey of La Trobe University. He himself has led some research projects on the codings and found that hardly any research had been done on them. The codes of interventions are unknown in many countries, which has led to other "attempting to reinvent the coding wheel". As regards the content of the codes, Carey makes various proposals for revision in an article from 2015. Among other things, he suggests moving away from the Christocentric formulations of the codes. He advocates supplementing "pastoral" with "religious" and "spiritual". The abbreviation PIC for "Pastoral Intervention Codes" therefore becomes REPSIC for "Religious, pastoral, spiritual Intervention Codes". ${ }^{8}$

The extent to which Spiritual Health Association is familiar with or has taken up Carey's research is not discussed in Hennequin's article. But attentive readers will have noticed that Hennequin's contribution indicates a further development of the intervention codes: while,

\footnotetext{
${ }^{7}$ Spiritual Health Association (SHA) as a "state peak body" for advancing the quality and availability of spiritual care in health services is supported by the State Government of Victoria and advised by a multi-faith board and council. SHA works in collaboration with all the faith communities that are SHV-members: Anglican, Baptist, Buddhist, Roman Catholic, Church of Christ, Hindu, Islamic Council, Jewish Council, Lutheran, Macedonian, Orthodox Christian Chaplaincy Council of Victoria, Presbyterian, Salvation Army, Sikh and Uniting Church. The following reflections therefore concern all the SHA-members and their spiritual care providers equally. For further information, see http://www.spiritualhealth.org.au/about.

${ }^{8}$ For the whole section, see Carey, L.B., and J. Cohen. 2015. The Utility of the WHO ICD-10-AM Pastoral Intervention Codings within Religious, Pastoral and Spiritual Care Research. Journal of Religion and Health 54:1772. 10.1007/s10943-014-9938-8
} 
in section three of the article, she speaks of Pastoral Codes, she refers to "updated Spiritual Intervention Codes" in section five. These are the official intervention codes currently in force, approved by the Australian Consortium for Classification Development in 2017: (1) Spiritual assessment; (2) Spiritual counselling, guidance or education; (3) Spiritual support; (4) Spiritual ritual; and (5) Allied health intervention, spiritual care. These updated codes incorporate many of Carey's recommendations, but they do not use the terms "religious" and "pastoral".

The intervention codes form the core of SHA's provision the reporting and documenting of spiritual care. The data that can be drawn from their use might thus be described as the minimum dataset to be collected according to SHA. The coding itself, however, does not yet say anything about the method to be used for documentation. The codes are not a method, not a tool, but a framework. When asked in the discussion, Hennequin pointed out that the given coding of interventions of the different spiritual care givers is no substitute for the careful choice of methods for the documentation of Spiritual Care. Rather, SHA only elaborates the general guidelines in which it specifies how something should be done. This also has to do with the fact that the different hospitals often use completely different information systems. While the interventions are classified (intervention codes) and must be adopted as specified by SHA; everything else is being adapted for each single system.

\section{Structural Distance and Participation}

Due to its organisational form, which is not operational but for the most part administrative, SHA needs reliable partners to implement its requirements on site. For this reason, Hennequin often points out in oral exchanges how important the maintenance of good relationships is for SHA's work. Ultimately, it is the functioning relationships with the local spiritual care managers in the hospitals that decide whether the guidelines drawn up for documentation address the questions and concerns of the practitioners and are therefore subsequently adhered to across the board. Unfortunately, the reader of the article does not learn anything about the evaluation of the content of the information sheets and documentation guidelines mentioned in section five. Especially in view of Australia's many years of experience with the intervention codes, these evaluations would be of great interest to other countries that are just beginning to standardise the documentation of spiritual care.

And what about the patients for whose sake a meaningful documentation is ultimately demanded and desired? The patients seem to be included in Hennequin's the previous article, but not mentioned. The change from Christian pastoral care to pluriconfessional spiritual care goes hand in hand with a new culture, as Hennequin emphasises, one which is oriented towards professionalisation and accountability. Documentation, in this context, stands in connection with the word "accountability". The intervention codes closely adhere to existing forms of medical documentation and suggest - albeit not in a billable form - an ordered, uniform and comprehensible procedure in the field of spiritual care, a professionalised and accountable practice of spiritual care. ${ }^{9}$ But is the application of the codes also perceived as appropriate? The voices of spiritual care employees are not the only relevant ones here. It would be extremely desirable and of great interest to gather opinions and

\footnotetext{
${ }^{9}$ Even though the interventions classified by the codes are not billable, the requirement for accountability has financial consequences for Spiritual Care Providers in Victoria. The Victorian State Government provides funding to SHA for the development and provision of spiritual care services in Victorian health services. Based on the 2016 census figures, half of the money is distributed by SHA to the faith communities that provide spiritual care in Victoria. In return, the communities are obliged to be accountable for their work. They present annual reports on financial expenditures, explaining what the communities do, where they work, whom they visit. If a report is missing, SHA can reduce the amount that the respective faith community receives annually to enable their provision of spiritual care services.
} 
experiences from patients. The desideratum of patient participation also came up several times in discussion at the workshop. Awareness of this seems to exist, but implementation is still in its infancy - even though a research partnership between SHA and La Trobe University is under consideration. It would be interesting to know the results.

\section{References}

Aiken, C. 2010. How we do Chaplaincy: A case study of South Australian Chaplains' understanding about their way of doing Chaplaincy. Retrieved May 28, 2018, from https://repository. divinity.edu.au/517.

Australian Commission on Safety and Quality in Health Care. 2017. National safety and quality health service standards, 2nd Ed. Sydney, NSW, Australia. Retrieved March 18, 2019, from https://www.safetyandquality.gov.au/our-work/assessment-to-the-nsqhs-standards.

Australian Health and Welfare Chaplains Association Inc. 2004. Health Care Chaplaincy guidelines. Australia.

Bossie, C. 2018. Data collection - Spiritual interventions codes from Jan 1st, 2018. Adelaide, South Australia, Australia. Retrieved May 29, 2018.

Gibbons, G.D. 1998. Developing codes for pastoral diagnoses and pastoral responses in hospital chaplaincy. Chaplaincy Today 14 (1): 4-13.

Healthcare Chaplaincy Council of Victoria Inc. 2012. HCCVI standards for reporting on pastoral care services in Victorian hospitals. Abbotsford.

Holmes, C. 2018. Stakeholder views on the role of spiritual care in Australian hospitals: An exploratory study. Health Policy. Retrieved May 27, 2018, from www.healthpolicyjrnl.com/article/ S0168-8510(18)30046-0/fulltext.

Independent Hospital Pricing Authority. 2018. Classifications. Retrieved from IHPA: www.ihpa. gov.au/what-we-do/non-admitted-care.

Kenny, J.M. 2003. A finger pointing to the moon. Mulgrave: John Garratt Publishing.

Marek, D.V. 2005. How much does it cost for Chaplains' services? Retrieved from National Association of Catholic Chaplains: www.nacc.org/vision/most-requested/ how-much-does-it-cost-for-chaplain-services.

Massey, K. 2015. What do I do? Developing a taxonomy of chaplaincy activities and interventions for spiritual care in intensive care unit palliative care. Retrieved May 25, 2018, from BMC Palliative Care: bmcpalliatcare.biomedcentral.com/articles/10.1186/s12904-015-0008-0.

National Centre for Classification in Health. 2002. ICD10-AM third edition education. Retrieved from ACPE Research: www.acperesearch.net/ICD_10_AM_3rd_ed_Education.pdf.

Safer Care Victoria. 2018. Home. Retrieved from health.vic: www2.health.vic.gov.au/ hospitals-and-health-services/safer-care-victoria.

Spiritual Care Australia. 2018. Towards New Horizons: Spiritual Care Australia conference. Program Guide, 14. Newcastle, NSW, Australia. Retrieved from Spiritual Health Victoria.

Spiritual Health Association. 2020. About us. Retrieved 27 February, 2020. https://spiritualhealth. org.au/about.

2019. February. Spiritual care in medical records: A guide to reporting and documenting spiritual care in health services. Abbotsford, Victoria, Australia. Retrieved February 27, 2020, from https://spiritualhealth.org.au/standards.

—. 2019a. Annual report 2018-2019. Retrieved from https://spiritualhealth.org.au/about Annual Report-2018-2019.pdf.

- 2019b. The spiritual Care state-wide survey report 2019 - Preliminary report. Victoria, Australia.

Spiritual Health Victoria. 2015. Spiritual care minimum dataset framework. Abbotsford, Victoria, Australia. 
2016. Standards and frameworks - Capability framework for spiritual care practitioners in Health Services 2016. Retrieved February 27, 2020, from Spiritual Health Association. https:// spiritualhealth.org.au/standards.

. 2018. Spiritual Care Management Network meeting. Melbourne, Victoria, Australia.

Victoria State Government. 2018a. Hospitals and health services: Casemix funding. Retrieved from health.vic: www2.health.vic.gov.au/hospitals-and-health-services/ funding-performance-accountability/activity-based-funding/casemix-funding.

2018b. Medical records. Retrieved from Freedom of Information: http://www.foi.vic.gov. au/home/foi/what+you+cannot+access/what+you+cannot+access+-+medical+records.

- 2018c. Allied health professions. Retrieved from health.vic: www2.health.vic.gov.au/ health-workforce/allied-health-workforce/allied-health-professions.

Victoria State Government Health and Human Services. 2017. National allied health standardised data development - Victorian Consultation. National. Melbourne, Victoria, Australia.

Victorian state Government. 2018. VAED criteria for reporting procedure code lists 2017-18. Retrieved from health.vic: www2.health.vic.gov.au/about/publications/policiesandguidelines/ vaed-criteria-for-reporting-procedure-code-lists-2017-18.

Open Access This chapter is licensed under the terms of the Creative Commons Attribution 4.0 International License (http://creativecommons.org/licenses/by/4.0/), which permits use, sharing, adaptation, distribution and reproduction in any medium or format, as long as you give appropriate credit to the original author(s) and the source, provide a link to the Creative Commons license and indicate if changes were made.

The images or other third party material in this chapter are included in the chapter's Creative Commons license, unless indicated otherwise in a credit line to the material. If material is not included in the chapter's Creative Commons license and your intended use is not permitted by statutory regulation or exceeds the permitted use, you will need to obtain permission directly from the copyright holder.

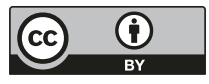

